\title{
The influence of shield gases on the surface condition of laser treated concrete
}

\author{
J. Lawrence and L. Li \\ Manufacturing Division, Department of Mechanical Engineering, University of Manchester Institute of \\ Science and Technology (UMIST), Manchester, M60 1QD, UK.
}

\begin{abstract}
This work aims to elucidate the effects of using $\mathrm{O}_{2}$, Ar and He shield gasses during the treatment of the ordinary Portland cement (OPC) surface of concrete with a high power diode laser (HPDL). The findings showed a marked difference existed in the surface condition of the concrete after HPDL treatment depending on the shield gas used. The use of $\mathrm{O}_{2}$ as the shield gas was seen to result in glazes with far fewer microcracks and porosities than those generated with either Ar or He shield gases. Such differences were found to be due to the smaller $\mathrm{O}_{2}$ gas molecules dissolving molecularly into the open structure of the HPDL generated glaze on the OPC surface of concrete and react with the glass network to increase the fluidity of the melt. This in turn was also seen to affect the cooling rate and therefore the tendency to generate microcracks.
\end{abstract}

Keywords: high power diode laser (HPDL), concrete, cement, gas, glaze

\section{Introduction}

Lasers have the propensity to be employed for the non-contact processing of materials which are otherwise difficult to process. Concrete is one such material since it is a composite, consisting of an array of fine and coarse aggregate pieces embedded within an ordinary Portland cement (OPC) matrix. The laser processing of concrete is a field of ongoing research, with many studies having been carried out to investigate the technique itself and the associated phenomena. Most of the research, however, has concentrated on the laser cutting of concrete and reinforced concrete using high power $\mathrm{CO}_{2}$ lasers, most prominently with regard to nuclear reactor decommissioning [1]. Work by Sugimoto et al. [2] focused upon modifying the surface appearance and surface properties of cement based materials using a high power $\mathrm{CO}_{2}$ laser. The resultant physical characteristics and mechanical behaviour of the post-process cement based materials was later fully characterised by Wignarajah et al. [3]. Borodina et al. [4] has carried out investigations into the structural changes within the composition of zirconia concrete caused by surface exposure to $\mathrm{CO}_{2}$ laser radiation, detailing microstructural changes, phase changes and the absorptivity characteristics. Yet in all of these studies, spallation and excessive cracking and porosity formation were found to be major problems undermining the laser treated surface layer. However, Lawrence and Li [5-7] have treated the OPC surface of concrete with both $\mathrm{CO}_{2}$ and high power diode lasers (HPDL). The HPDL generated OPC glaze was shown to be more than an effective surface modification insofar as it provided superior mechanical, physical and chemical characteristics over an untreated or $\mathrm{CO}_{2}$ laser treated OPC surface.

*Corresponding author: tel: +44 161 236-3311; fax: +44 161 200-3803; e-mail: j.lawrence@umist.ac.uk 
Investigations into the effects of different shield gases during the laser processing of materials have hitherto focused mainly on the laser welding and cutting of steels, with other studies examining the laser ablation drilling and surface treatment of numerous metals. These studies have revealed the high degree of influence that the shield gas employed has on the process and end results $[8,9]$. In a study into the influence of shield gas type on the surface characteristics of the welds generated on steel with a $\mathrm{CO}_{2}$ laser. To date, a number of workers have reported on the effects of shield gases during laser drilling. In particular, detailed studies by Low et al. [10] revealed that, whereas the use of an $\mathrm{O}_{2}$ shield gas typically caused increased liquid particle ejection coupled with volatile burning, the use of an Ar shield induced material ejection predominantly by bulk radial liquid ejection.

Porosity and microcracking are attendant problems when laser treating the surface of many materials, with cement and concrete being no exception. It is known, however, that certain shield gasses can go some way to assuage or even eliminate the serious problems of surface porosity and microcracking. This work aims to elucidate the effects of using $\mathrm{Ar}, \mathrm{O}_{2}$ and $\mathrm{He}$ shield gasses during the treatment of the OPC surface of concrete with a HPDL. The findings showed a marked difference existed in the surface condition of the concrete after HPDL treatment depending on the shield gas used.

\section{Experimental procedures}

The concrete studied in the experiments was the ubiquitous OPC based concrete. For the purpose of experimental convenience the as-received concrete blocks were sectioned into cubes $\left(120 \times 120 \times 20 \mathrm{~mm}^{3}\right)$ prior to laser treatment. In order to obtain results of a practical and useful nature, the area of the concrete irradiated during the experiments was the naturally occurring 'as cast' OPC surface of concrete. In this case the OPC surface of the concrete had a thickness of $2.5 \mathrm{~mm}$. The composition by volume of the OPC is as follows: $\mathrm{CaO}$ (63.9\%), $\mathrm{SiO}_{2}$ (21.9\%), $\mathrm{Al}_{2} \mathrm{O}_{3}$ (5.7\%), $\mathrm{Fe}_{2} \mathrm{O}_{3}(2.8 \%), \mathrm{SO}_{3}(2.7 \%), \mathrm{MgO}(2.2 \%), \mathrm{K}_{2} \mathrm{O}(0.7 \%)$ and $\mathrm{Na}_{2} \mathrm{O}(0.1 \%)$.

The laser used in this work was a HPDL (Diomed Ltd.) emitting at $810 \pm 20 \mathrm{~nm}$ with a maximum output power of $120 \mathrm{~W}$. The HPDL beam was delivered to the work area by means of a $4 \mathrm{~m}$ long, $600 \mu \mathrm{m}$ core diameter optical fibre, the end of which was connected to a 2:1 focusing lens assembly. The laser was operated in the continuous wave $(\mathrm{CW})$ mode and produced a multi-mode beam. The defocused laser beam was fired across the OPC surface of the concrete samples by traversing the samples beneath the beam using the $\mathrm{x}$ - and $\mathrm{y}$-axis of a CNC gantry table at speeds ranging from $60-600 \mathrm{~mm} \mathrm{~min}^{-1}$. So as to study the effects of different shield gasses, coaxially blown gas jets of $\mathrm{O}_{2}, \mathrm{Ar}$ and He were applied at a rate of $51 \mathrm{~min}^{-1}$.

\section{Results}

The constituents of OPC are minerals which exist as multi-component solid solution chemical compounds. Of particular importance with regards this study, OPC contains in relatively large proportions $\mathrm{SiO}_{2}, \mathrm{Al}_{2} \mathrm{O}_{3}$ and $\mathrm{Fe}_{2} \mathrm{O}_{3}$, which are basic glass network formers and modifiers. Consequently the intense local heating brought about by the incident HPDL beam results in melting of these compounds at around $1283^{\circ} \mathrm{C}$, thereby causing the materials to lose the retained water and form an amorphous glassy material consisting of various calcium-silicate-alumina compounds. Indeed, the amorphous nature of this glaze has been verified and fully characterised by Lawrence and Li [8-10].

Variations in the shield gas used during the HPDL irradiation of the OPC surface of concrete were seen to have a significantly effect on the surface morphology of the HPDL induced glaze. Fig. 1 shows a typical optical surface view of the HPDL treated OPC surface of concrete with (a) $\mathrm{O}_{2}$, (b) Ar and (c) He shield gases. 

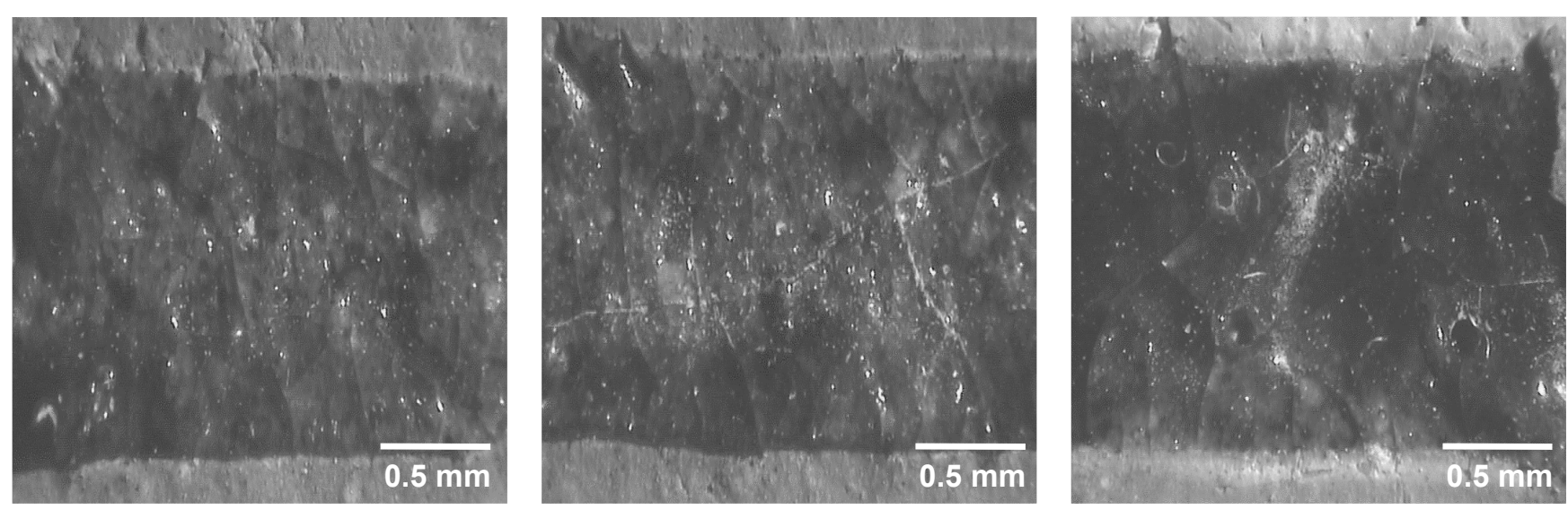

Fig. 1. Typical optical surface morphology of the OPC surface HPDL glaze generated with (a) an $\mathrm{O}_{2}$, (b) an Ar and (c) a He shield gas. (2.25 $\mathrm{kW} \mathrm{cm}^{-2}$ power density, $240 \mathrm{~mm} \mathrm{~min}^{-1}$ traverse speed)



Fig. 2. Best-fit cooling rate curves for the laser glazed $\mathrm{OPC}$ surface of concrete when $\mathrm{O}_{2}$, $\mathrm{Ar}$ and $\mathrm{He}$ shield gases were employed.

As is evident from Fig. 1, the use of $\mathrm{O}_{2}$ as the shield gas results in surface glazes that exhibit far fewer microcracks and porosities than those generated with either Ar of He shield gases. Indeed, as one can see from Fig 1(a), the glaze generated on the OPC surface of concrete when using an $\mathrm{O}_{2}$ shield gas appears to have very few microcracks and almost no porosities. In contrast, the glaze generated on the OPC surface of concrete when He was employed as the shield gas can be seen to posses a great many microcracks and numerous porosities (Fig. 1(c)). The glaze produced on the OPC surface of concrete when using and Ar shield gas appears similar (Fig. 1(b)), although the number of microcracks present seems to be somewhat less than when a He shield gas was used.

The findings of an investigation to study the temperatures on the surface of the OPC resulting from HPDL interaction with the selected shield gases are shown graphically in Fig. 2. As can be seen clearly from Fig. 2 , the recorded cooling rate of the OPC surface under a He shield gas after the HPDL beam has been removed was slightly faster than that when Ar was used as the shield gas. Moreover, Fig. 2 shows that a 
cooling rate considerably slower than those occasioned by the use of either Ar or $\mathrm{He}$ as the shield gas resulted from employing an $\mathrm{O}_{2}$ shield gas.

\section{Discussion and conclusions}

Because of its open structure, it is possible for gases to dissolve molecularly in glass and, if the gas molecule is small enough, it can diffuse rapidly in a simple glass such as fused silica [11]. Indeed, gases such as $\mathrm{H}_{2}$ and $\mathrm{O}_{2}$ are known to dissolve molecularly in glass and can also react with the glass network [11]. The quality of the glazes produced, in terms of porosity and microcracks, was greatly influenced by the type of shield gas employed. When using any of the shield gases the surfaces appeared undulated and displayed porosities to varying degrees. Moreover, the crack density in the He and Ar shield gas samples were found to be higher than that of the sample treated with an $\mathrm{O}_{2}$ shield gas.

The use of $\mathrm{O}_{2}$ as the shield gas significantly reduced the number of microcracks and porosities within the OPC glaze. This implies that the $\mathrm{O}_{2}$ interacted with the glass network increasing the heat generation and subsequently the fluidity of the melt. In contrast, the He and Ar did not interact with the glass network and was consequently trapped within the more viscous melt in the form of bubbles. As such, when employing $\mathrm{O}_{2}$, inherent gas bubbles generated during vitrification of the OPC escaped from the melt more readily due to its lower viscosity, thus reducing the number of porosities. In addition, as the cooling rate curves for the HPDL treated OPC surface of concrete shown in Fig. 2 indicate, when the laser beam had been removed the cooling of the OPC was faster when $\mathrm{He}$ and Ar shield gases were employed as opposed to an $\mathrm{O}_{2}$ shield gas. Therefore, the length of time that the OPC surface of concrete is of a sufficient fluidity to allow the generated gas bubbles to escape the surface easily is much reduced, resulting in porosities and microcracks.

The marked reduction in the number of microcracks generated when using an $\mathrm{O}_{2}$ shield gas instead of He or Ar can also be ascribed to the apparent much reduced cooling rate occasioned by the use of $\mathrm{O}_{2}$ as the shield gas. This is borne out somewhat when one considers that He is known to effect a higher rate of cooling than both $\mathrm{O}_{2}$ and particularly $\mathrm{Ar}$ [8]. Clearly, the tendency of the HPDL induced glaze on the OPC surface of concrete will be reduced if the cooling rate of the molten OPC is reduced. This is principally because a high cooling rate inherently induces thermal stresses which in turn can lead to crack development in order to relieve the generated thermal stresses.

\section{References}

1. K. Sugita, M. Mori, T. Fujioka, Concrete Eng. 24 (1986) 13.

2. K. Sugimoto, S. Wignarajah, K. Nagasi, S. Yasu, Proc. of ICALEO '90: Laser Materials Processing, Boston, USA, 1990, 302.

3. S. Wignarajah, K. Sugimoto, K. Nagai, Proc. of ICALEO '92: Laser Materials Processing, Orlando, USA, 1992, 383.

4. T.I. Borodina, G.E. Valyano, N.I. Ibragimov, E.P. Pakhomov, A.I. Romanov, L.G. Smirnova, P.K. Khabibulaev, J. Phys. and Chem. of Mater. Treatment 25 (1995) 541.

5. J. Lawrence, L. Li, Mater. Sci. Eng. A, 284 (2000) 93.

6. J. Lawrence, L. Li, Mater. Sci. Eng. A, 287 (2000) 25.

7. J. Lawrence, L. Li, J. Laser Apps. 72 (2000) 8.

8. D.H. Abbott, C.E. Albright, J. Laser Apps. 6 (1994) 69.

9. C. Bagger, G. Broden, E. Beske, F. Olsen, Int. J. Joining of Mater. 6 (1994) 68.

10. D.K.Y. Low, L. Li, A.G. Corfe, J. Eng. Manuf. 259 (2000) 42.

11. R.H. Doremus, Glass Science, John Wiley \& Sons, New York, 1994, pp. 154-160. 